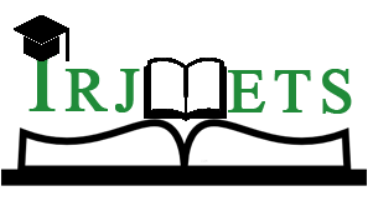

e-ISSN: 2582-5208

International Research Journal of Modernization in Engineering Technology and Science

Volume:03/Issue:04/April-2021

Impact Factor- 5.354

www.irjmets.com

\title{
ASSESSMENT OF THE CONDITION OF THE NEAR-WELLBORE ZONE OF
}

REPAIRED WELLS BY THE SKIN FACTOR

\section{Chang WJ ${ }^{* 1}$, AL-Obaidi SH ${ }^{* 2}$, Patkin $\mathrm{AA}^{* 3}$}

${ }^{*} 1$ Doctoral candidate, Department of Petroleum Engineering, Mining Institute

${ }^{*}$ Professor, Department of Petroleum Engineering, Mining Institute

${ }^{*}$ Associate Professor, Independent researcher, Scientific Research Center

\section{ABSTRACT}

Production wells that have penetrated low-permeability reservoirs do not provide adequate oil production due to the degraded condition of the near-wellbore zones of the reservoir. Objective assessment of the condition of the near-wellbore formation zone of exploration and production wells by determining the magnitudes and values of skin effects using well tests allows timely implementation of measures to increase the productivity of wells and oil production.

In this article, the following aspects of difficult-to-recover oil production were examined:

- The analysis of the dependence of well productivity on the magnitude and significance of the skin effect, in order to assess the condition of the bottomhole formation zone for further planning and implementation of oil and gas inflow stimulation measures;

- The influence of the magnitude and significance of the skin effect on the condition of the bottomhole formation zone on the experience of developing exploration wells penetrated into low-permeability formations in the fields of Western Siberia;

- Criteria (based on the value and magnitude of the skin effect) for selecting methods of stimulating the bottomhole formation zone to increase the productivity of low-rate wells.

Keywords: Skin factor, Bottomhole zone, Well productivity, Flow rate, Repaired wells, Low permeability.

\section{INTRODUCTION}

One of the most common methods of assessing the condition of the bottomhole zone is to determine the skin factor. The skin factor, or in other words, the skin effect, is a dimensionless complex indicator that characterizes the additional pressure losses for a hydrodynamically sound well in the adjacent formation zone. It is generally assumed that positive values of the skin factor are characteristic of the condition of the near-wellbore zone, which is deteriorated in relation to the distant part of the formation, negative - for the improved one. In particular, when repairing wells, the skin factor is usually a negative value [1-3].

The skin factor is determined when processing well test data in transient mode with the construction of pressure build-up curves (PBU)[4-6].

In the paper [7], the following formula was proposed to determine the value of skin effect,

$$
S=1,151\left[\frac{\Delta P_{w f}^{(t)}}{i}-\log (t)-\log \frac{\Re}{r_{w}^{2}}-o, 35 i\right]
$$

Where $t$ is the time after shut-in the well, corresponding to any point of the straight section on the PBU, s; $\Delta \mathrm{P}_{\mathrm{wf}}$ increase in bottomhole pressure after shut-in the well, corresponding to time $\mathrm{t}, \mathrm{kgf} / \mathrm{cm}^{2} ; \mathrm{i}$ - the slope of the straight section of the PBU; $r_{w}$ is the radius of the borehole along the bit, $m$; $æ$ - coefficient of pressure diffusivity, $\mathrm{cm}^{2} / \mathrm{s}$.

The coefficient of pressure diffusivity is determined for a distant formation zone according to the formula proposed by VN Shchelkachev [8-10].

$$
æ=\frac{k}{\mu\left(\varphi \beta_{f}-\beta_{m}\right)}=\frac{k}{\mu \beta}
$$

Where $\beta_{\mathrm{f}}$ and $\beta_{\mathrm{m}}$ are the coefficients of compressibility of the fluid and formation; $\beta^{*}$ - is the coefficient of reservoir elasticity, $\mathrm{Pa}^{-1} ; \phi$ - effective porosity, unit fraction; $\mu$ - dynamic viscosity, $\mathrm{Pa}$.s. 


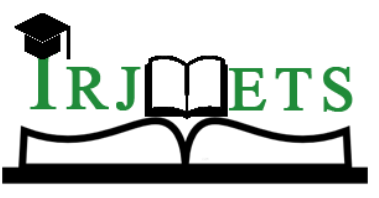

e-ISSN: 2582-5208

\section{International Research Journal of Modernization in Engineering Technology and Science}

Volume:03/Issue:04/April-2021

Impact Factor- 5.354

www.irjmets.com

During the well testing, it was found that the bottomhole formation zone of the studied wells is deteriorated in most cases. This is evidenced by low permeability and positive values of skin effect. This is the reason for the low production rate of the wells. For clarity, the obtained data can be represented graphically in the form of a relationship between the value of the skin factor(S) and the flow rate, Q (Fig. 1).

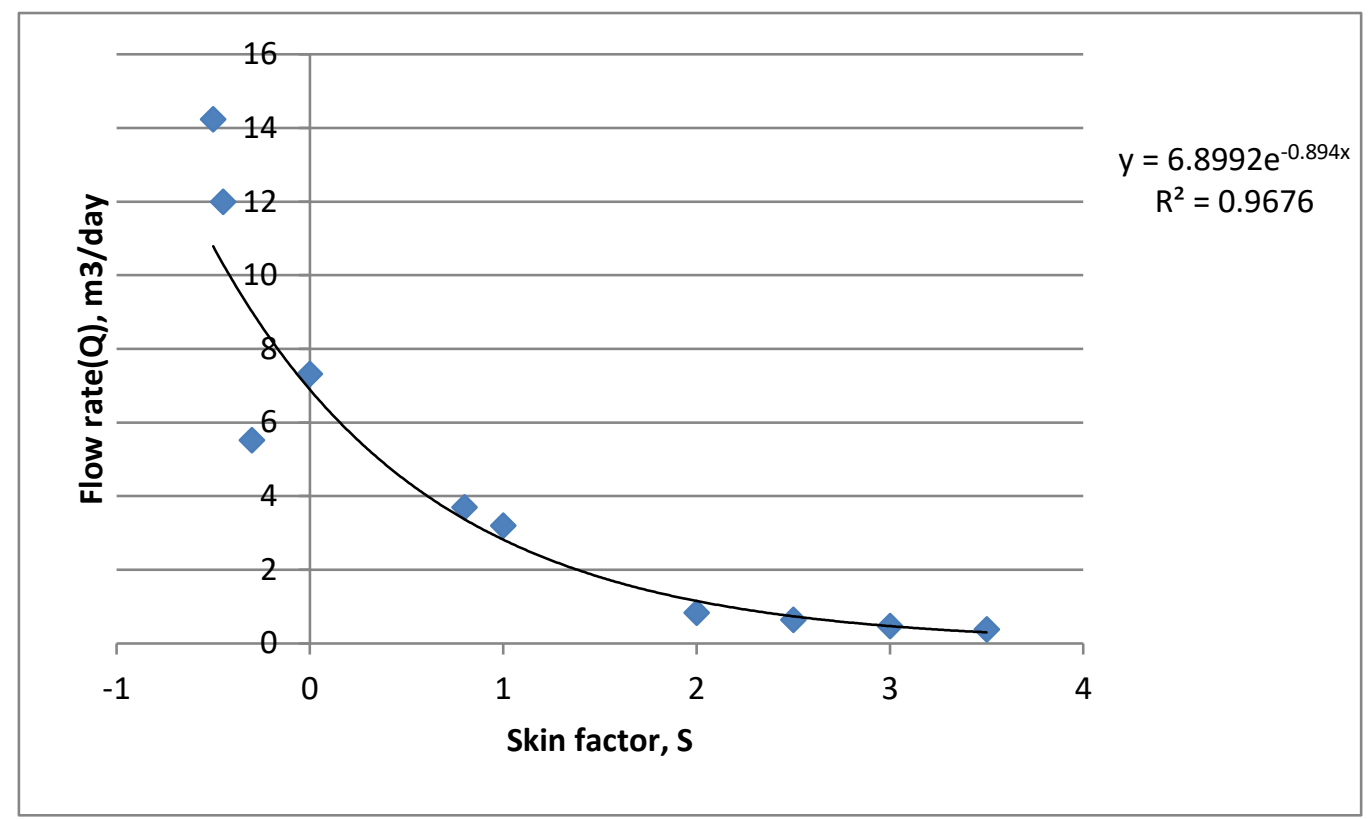

Figure 1 : Dependence of the well flow rate on the value of the skin factor

We will also present a graphical relationship between the productivity index and the value of the skin effect (Fig. 2)

On these graphs (see Figs. 1, 2), it can be seen that for positive values of the skin effect, the flow rate of the studied objects tends to zero. A higher reliability is observed in Fig. 1, which shows the change in the production rate [28-30].

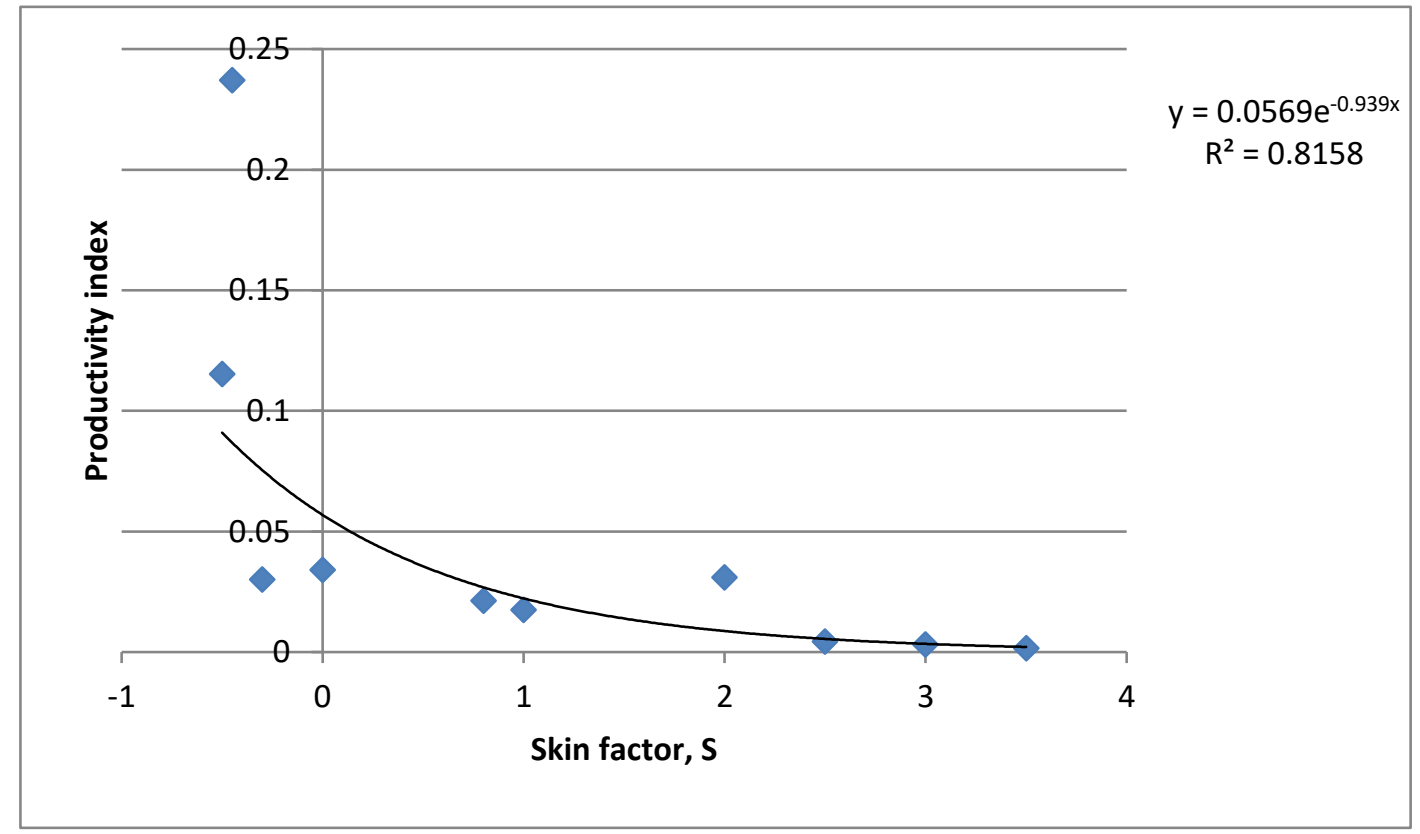

Figure 2: Dependence of well productivity on the value of the skin effect

Special attention should be paid to the Jurassic deposits of the U-formation under study. According to the obtained data, the dependence of the productivity and the flow rates on the magnitude and significance of the skin effect is described in (Figs. 3, 4). 


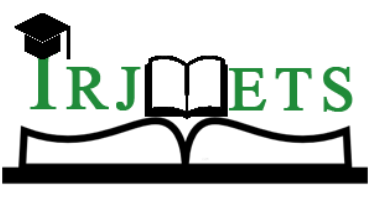

e-ISSN: 2582-5208

International Research Journal of Modernization in Engineering Technology and Science Volume:03/Issue:04/April-2021 Impact Factor- 5.354 www.irjmets.com

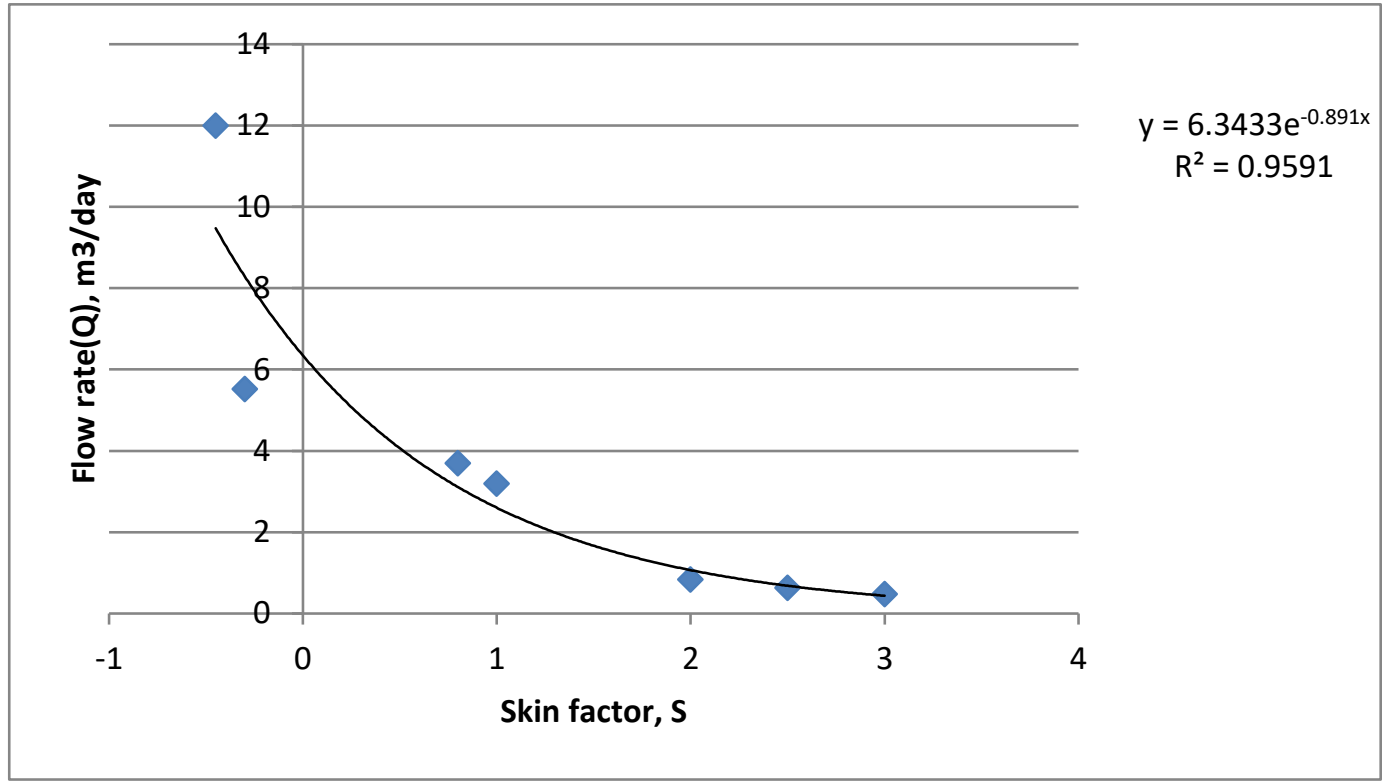

Figure 3: Dependence of the production rate of U-formation wells on the value of the skin effect.

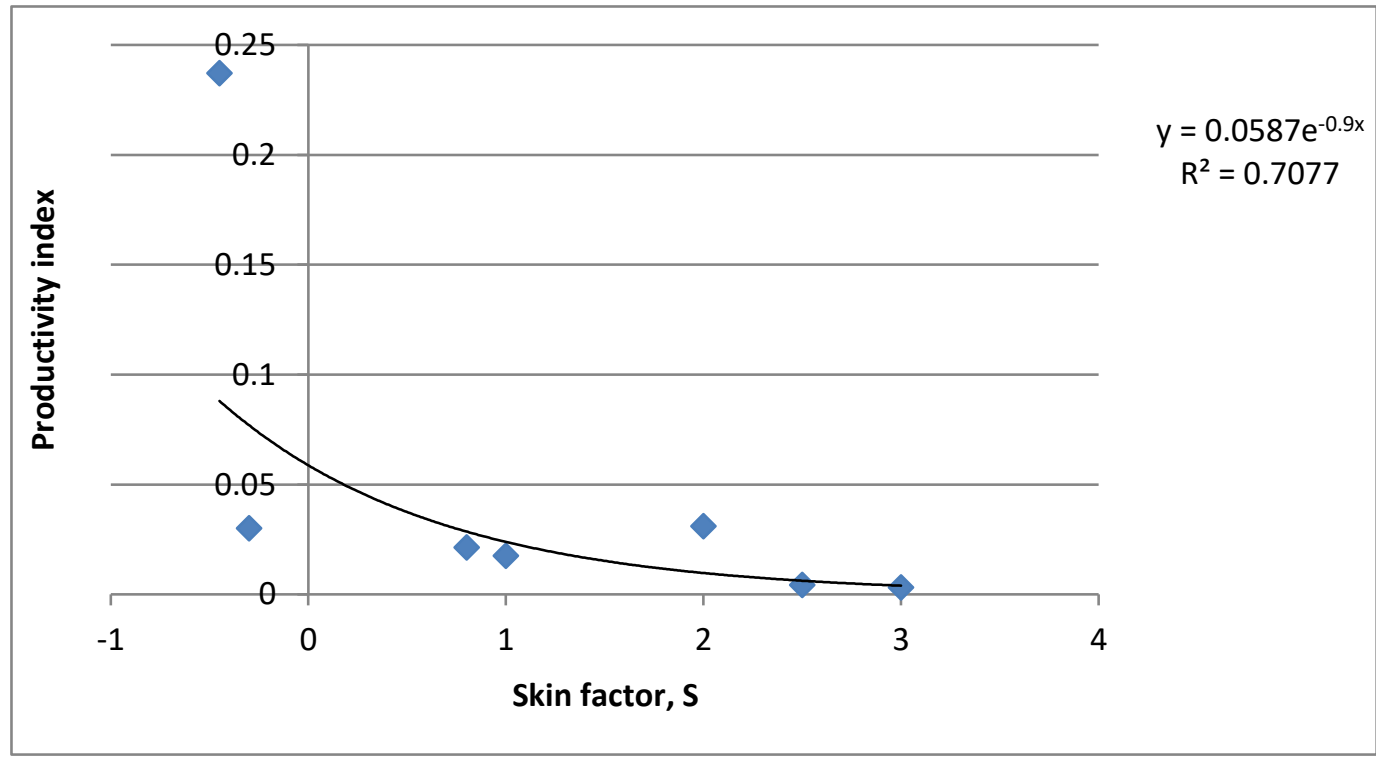

Figure 4: Dependence of the productivity of U-formation wells on the value of skin effect.

It should be noted that in almost all published works related to the study of the U-formation, there is a high heterogeneity and a complex geological structure. The heterogeneity of reservoirs often manifests itself in the form of high variability in total and effective thickness, local thinning of deposits and clay zones [31-33]. Therefore, in many fields within individual layers zones with completely different values of flow rates and productivity are found, which in our case for layer Yu vary from 0.48 to $12 \mathrm{~m}^{3}$ / day, from 0.003 to $0.237 \mathrm{~m}^{3} /$ day $/ \mathrm{kgf} / \mathrm{cm}^{2}$.

\section{STIMULATION TECHNOLOGIES}

Technologies to stimulate and increase the productivity of wells are of paramount importance for ensuring oil production, including in Western Siberia, and this issue is given special attention. The main methods of enhanced oil recovery in the region include physical, hydrodynamic and chemical.

The main tasks in the development of enhanced-oil recovery technologies are to equalize the permeability of heterogeneous reservoirs, to create resistance to fluid flow in washed-out zones of the reservoir, and to intensify flow in stagnant oil-saturated zones. 


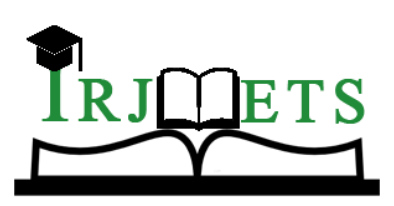

e-ISSN: 2582-5208 International Research Journal of Modernization in Engineering Technology and Science Volume:03/Issue:04/April-2021

Impact Factor- 5.354

www.irjmets.com

At positive values of skin effect it is recommended to carry out treatment of formation zone at the bottom of the well to increase oil recovery, for example, at values of skin effect from 0 to +3 it is recommended to comprehensively affect formation zone at the bottom of the well by vibration wave technologies in chemically active media (clay acid treatment, hydrochloric acid, surfactants, solvents) using jet pumps [34-36].

This technology will reduce the time required to clean the formation zone at the bottom of the well of the products of drilling fluid intrusion and increase well productivity. To effectively stimulate the formation and increase permeability, it is necessary to perform preliminary vibratory stimulation at the bottom formation zone of the wellbore at several locations without pumping fluid into the formation. In the reservoir there are stagnant areas of fluids - their "striding", weakening of the bonds of the fluid and contamination of particles with the reservoir skeleton.

Then it is necessary to pump the chemical composition into the reservoir through a vibration generator, installing a packer above the perforation interval, which makes it possible to affect the stagnant zones and form new flow channels $[37,38]$. The peculiarity of this technology is the cyclic process of action of the active fluid on the formation by the method "injection - depletion". This process keeps the fluid in the bottom zone in a dynamic state, the dynamics of the fluid brings insoluble reaction products into motion and prevents the formation of associations.

After the completion of the treatment of the bottomhole zone of the well (BHZ) with active fluid, the downhole equipment is changed to an assembly that includes a philtre with electronic pressure gauge, a packer installed directly above the perforation interval and a jet pump.

As a result of implementing this technology, inflow exceeding the original by 2-3 times has been achieved at the exploration wells.

At skin effect values of +3 to +5 , it is recommended to carry out micro-fracturing, the so-called local (small) hydraulic fracturing, which is an effective means of influencing the bottomhole formation zone to eliminate flow resistance (skin effect) [39,40].

In this case, it is enough to create fractures with a length of not more than $30 \mathrm{~m}$ and inject a few tons of propane, and the production rate of wells increases by 5-7 times, which is confirmed by the result of this technology in exploratory drilling of various hydrocarbon fields.

\section{CONCLUSION}

The dependence of well productivity on the size and significance of the skin effect has been determined at a number of fields and areas of Western Siberia. For example, for U-Reservoir, flow rates and productivity vary from 0.48 to $12 \mathrm{~m}^{3}$ / day and from 0.003 to $0.237\left(\mathrm{~m}^{3} /\right.$ day $\left./ \mathrm{kgf} / \mathrm{cm}^{2}\right)$, respectively.

For further planning and implementation of measures to stimulate oil and gas inflows, the condition of the bottomhole formation zone of exploration wells as well as repaired wells was evaluated from the point of view of skin effect.

At skin effect values from 0 to +3 , it is recommended to carry out extensive influence on the bottomhole formation zone by vibration wave technologies in chemically active media (clay acid treatment, hydrochloric acid, surfactants, solvents) with the help of jet pumps. Micro-fracturing is recommended for skin effect values of +3 to +5 .

The improvement of efficiency in the development of new oil fields and, above all, the further development of long-term oil fields is possible only through the widespread industrial use of artificial methods for controlling the productivity of wells. Special attention should be paid to low-yield wells, the number of which, unfortunately, is increasing, and on the efficiency of work with such a fund depends both the total oil production in the country and the cost of oil production.

\section{REFERENCES}

[1] Shagiev R. G., Levchenko I. Yu. "Analysis of the components of the skin factor on the example of studies of wells of the Pas-minno-Sasovsky field", Oil economy, No. 12. - pp. 67-69,2002.

[2] Chang W.J. , AL-Obaidi S.H., Patkin A.A. "The Use Of Oil-Soluble Polymers To Enhance Oil Recovery In Hard To Recover Hydrocarbons Reserves", International Research Journal of Modernization in Engineering Technology and Science, Vol. 03, Issue 01 , pp 982-987, 2021.

[3] Al-Obaidi Sudad H. (1996). “Разработка Методики И Технологии Обработки Данных ГИС.” OSF 


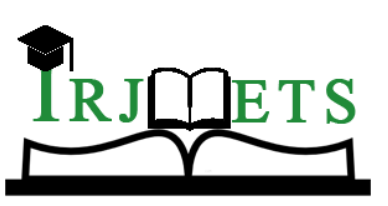

e-ISSN: 2582-5208

International Research Journal of Modernization in Engineering Technology and Science

Volume:03/Issue:04/April-2021

Impact Factor- 5.354

www.irjmets.com

[25] Al-Obaidi SH and Khalaf FH "Prospects for improving the efficiency of water insulation works in gas

wells", International Research Journal of Modernization in Engineering Technology and Science, Vol. 2, Issue 9, pp 1382-1391, 2020.

[26] Kustyshev A. V., Panikarovskiy E. V., Kustyshev D. A. "Production intensification at the final stage development of deposits in Western Siberia, Gas Industry, No. 7, pp 23-25, 2014.

[27] Al-Obaidi SH , Galkin AP and Patkin AA. "Prospects of High Viscosity Oil Flow Rate in Horizontal Wells", JoPET , Vol. 5, Issue 4, pp 56-62, 2006.

[28] Al-Obaidi Sudad H. 2004. "Modified Use of Microbial Technology as an Effective Enhanced Oil Recovery." OSF Preprints, doi:10.31219/osf.io/xgthz.

[29] Al-Obaidi, Sudad H and Guliaeva NI (2017) "Thermal Adsorption Processing of Hydrocarbon Residues", International Journal of Scientific \& Technology Research, 6(4):137-140.

[30] VI, S., \& AL-Obaidi, S. H. (2021, January 25). Innovative methods of enhanced oil recovery. https://doi.org/10.31224/osf.io/z3bku

[31] Al-Obaidi Sudad H., Patkin AA, and Guliaeva NI. 2020. "Advance Use for the NMR Relaxometry to Investigate Reservoir Rocks." OSF Preprints, doi:10.31219/osf.io/jmb9t.

[32] AL-Obaidi, Sudad H., et al. "Changes in the Physical Properties of Hydrocarbon Reservoir as a Result of an Increase in the Effective Pressure During the Development of the Field." engrXiv, 18 Feb. 2021. Web

[33] Sudad H AL-Obaidi, "A way to increase the efficiency of water isolating works using water repellent", International Research Journal of Modernization in Engineering Technology and Science, Vol. 2, Issue 10, pp 393-399, 2020.

[34] Shagiev RG "Well research by pressure build-up", M : Nauka, p 304, 1998.

[35] AL-Obaidi, SH and Guliaeva, NI and Smirnov VI (2020). Influence of structure forming components on the viscosity of oils. International Journal Of Scientific \& Technology Research, Vol. 9, Issue 11, 347351.

[36] AA, Patkin, and Sudad H. AL-Obaidi. "Influence of Temperature and Pressure of Incoming Oil-containing Liquid from Field Wells on the Gas Separation Process", Journal of Petroleum Engineering and

Emerging Technology, Volume 3, Issue 4, pp 20-24, 2001.

[37] AL-Obaidi SH , Smirnov VI and Kamensky IP . "Investigation of rheological properties of heavy oil deposits", International Journal Of Scientific \& Technology Research, Vol. 8, Issue 09, pp 2394-2397, 2019.

[38] Suleimanov BA On the influence of the skin effect on the flow rate of oil wells // Geology, Geophysics and Development oil and gas fields. - 2004. - No. 8. - S. 68-70.

[39] AL-Obaidi, Sudad H., et al. "Investigation Of Thermal Properties Of Reservoir Rocks At Different Saturation." engrXiv, 14 Dec. 2020. Web.

[40] AL- Obaidi SH, Smirnov VI, Khalaf FH "New Technologies to Improve the Performance of High Water Cut Wells Equipped With ESP", Technium, Vol. 3, Issue 1, pp 104-113, 2020. 